\title{
14. GROWTH STUDIES ON GLOBOROTALIA EXILIS BLOW AND GLOBOROTALIA PERTENIUS BEARD IN THE HOLE 154A SECTION, LEG 15, DEEP SEA DRILLING PROJECT
}

\author{
Richard K. Olsson, Geology Department, Rutgers University, New Brunswick, New Jersey
}

\section{INTRODUCTION}

Drilling at Hole 154A cored continuously through the Globorotalia miocenica-Globorotalia exilis and Globorotalia margaritae zones (Bolli, 1970). The species Globorotalia exilis Blow and the related Globorotalia pertenuis Beard are abundant and well-developed throughout their stratigraphic ranges in these zones. They had upon cursory examination seemed to exhibit certain interesting growth features that warranted a closer quantitative examination. Previous growth studies of planktonic foraminifera (Olsson, 1971) show that growth of chambers in the coiled shell is geometric. In these studies it was shown that in one of the species analyzed, growth followed a single geometric series, whereas in another, which was followed throughout its evolutionary development to its extinction level (The Globorotalia foshi series), growth followed a more complex pattern (Olsson, 1972). The G. exilis - G. pertenuis sequence exhibited clear indications that growth patterns were complex. Thus it is possible in the Hole 154A section to study the growth characteristics of these taxa over their stratigraphic range and to determine the nature, and perhaps the significance, of growth changes that may have occurred prior to the extinction of the lineage.

Measurements of chamber width, radius, and angle of rotation were taken on each chamber throughout ontogeny of individuals of $G$. exilis and $G$. pertenuis selected randomly from samples taken from various stratigraphic levels of their ranges. This method of studying growth of planktonic foraminiferal species follows that of Olsson (1971).

Graphs of chamber width, radius, and allometry of chamber width-radius were made on all specimens. All measurements on individuals were taken from scanning electron micrographs of an oriented dorsal view (Plate 1). All linear measurements were converted to correspond to a magnification of 50 times for comparison purposes and ease of graph construction.

\section{GROWTH AND GROWTH PATTERNS}

A useful analogy to the geometric expansion of chambers during growth of a planktonic foraminiferal shell can be made with an inflating balloon. The shape during geometric growth does not change but the size does. Within limits the balloon can be inflated to any desired size. The secretion of chambers in the planktonic foraminifera occurs at various stages of inflation similar to the size changes of the inflating balloon when the inflator pauses for breath. In the inflating balloon there are an infinite number of sizes that can occur at any one stage of growth. This is also true in the planktonic foraminifera and can be observed in the variations in size dimensions of chambers in a selection of specimens. Thus there is no definite sequence of chamber sizes in the coiled shell of the foraminifera, but rather it would appear that the size of each chamber is controlled by the requirements of the constructed shell and the growth pattern which directly effects the construction of the test. The size level during growth is also an important function during growth of the test.

The following example illustrates what is meant by size level. If two individuals have the same growth rate their growth curves will be identical. They may not coincide with one another, however, because growth may have started at a higher size level in one than in the other. Thus in Figure 1a the growth curves of the two individuals are identical but parallel. The size level, on the other hand, may change during the growth of an individual so that, in the simplest case, growth is on two levels (Figure 1b). An early string of chambers grows at one size level; then, an abrupt jump to a different size level follows, and the remainder of the chambers grow along the new size level. An interesting aspect of size level change during ontogeny is that it is often the case that not all chamber dimensions change to the new size level at the same time. There may be a lag of a chamber or two before all chamber dimensions have changed to the new size level. (Compare Figure $1 \mathrm{~b}$ to $1 \mathrm{c}$.) A more complicated pattern occurs where growth takes place on a range of size levels moving either to lower levels, higher levels, or both. In this case (Figure 1d) a wide range of variations can be produced from individual to individual as to what size level is used, when it is used, and in what direction the size level change takes place. The latter pattern is the one observed in the $G$. exilis $-G$. pertenuis group. A definite change apparently occurred in this basic pattern during the evolutionary transition of $G$. pertenuis into $G$. exilis.

\section{GROWTH PATTERN OF GLOBOROTALIA EXILIS AND GLOBOROTALIA PERTENIUS}

The growth pattern of $G$. exilis appears to exhibit a somewhat ordered sequence of chamber growth (Figure 2). The growth pattern is complex with periodic interruptions to different growth levels, but the geometric growth rate appears to be similar throughout ontogeny. Throughout the ontogeny of this taxon the change of growth level is generally to a lower one so that the growth curve resembles a series of step-downs. Occasionally a slight jump to a higher growth level occurs but this is followed by a step-down to a lower level or to a level similar to the one prior to the step-up. Usually the step-up involves only two chambers. An allometric relationship is maintained, nevertheless, throughout the ontogenetic development of the test. Termination of growth is always preceded by a recognizable slowing of growth in chamber dimensions. 


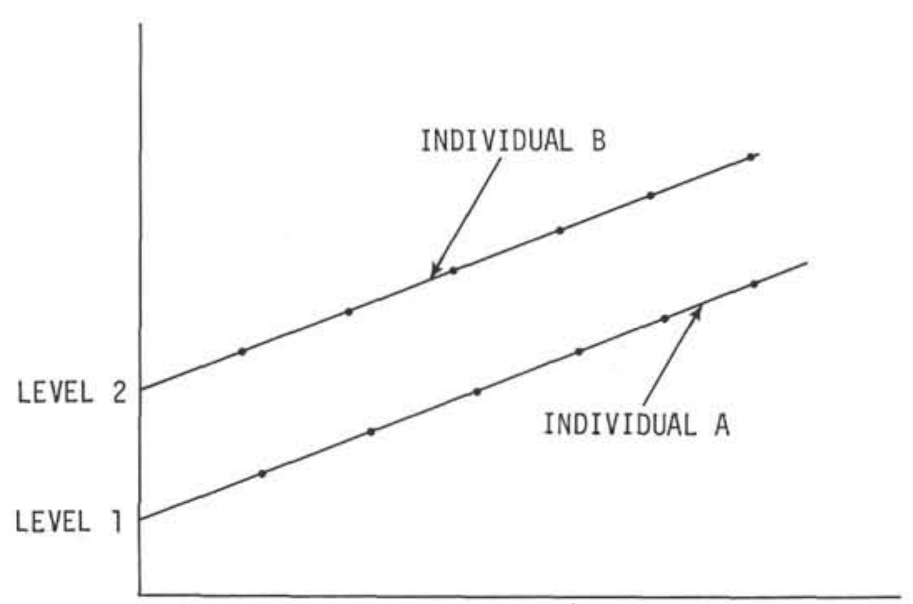

a

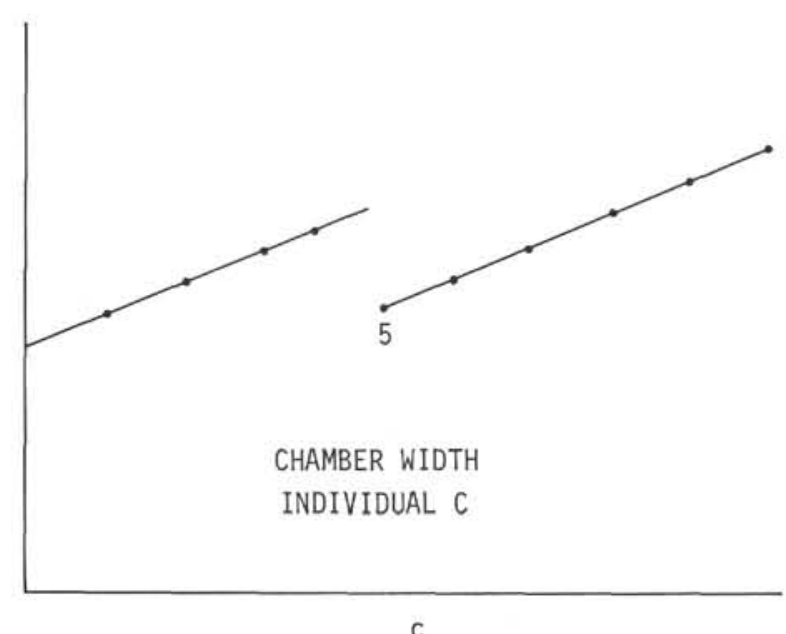

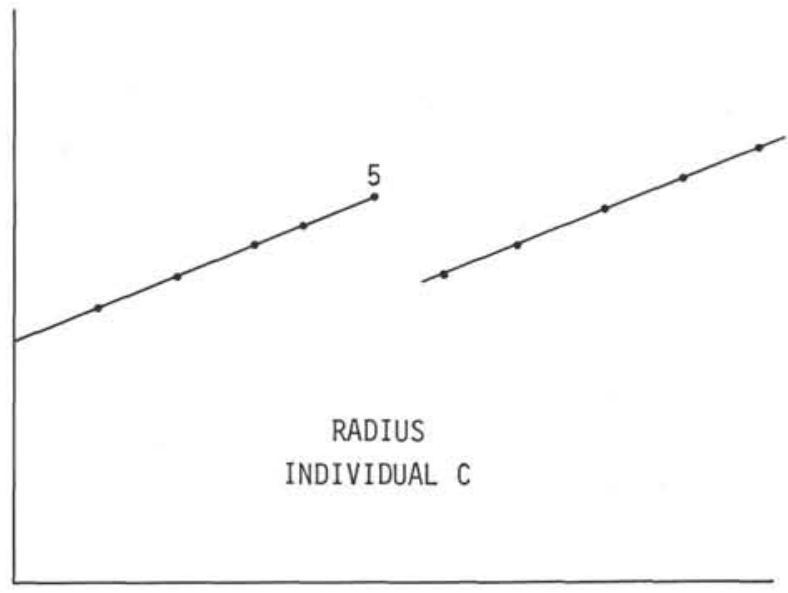

b

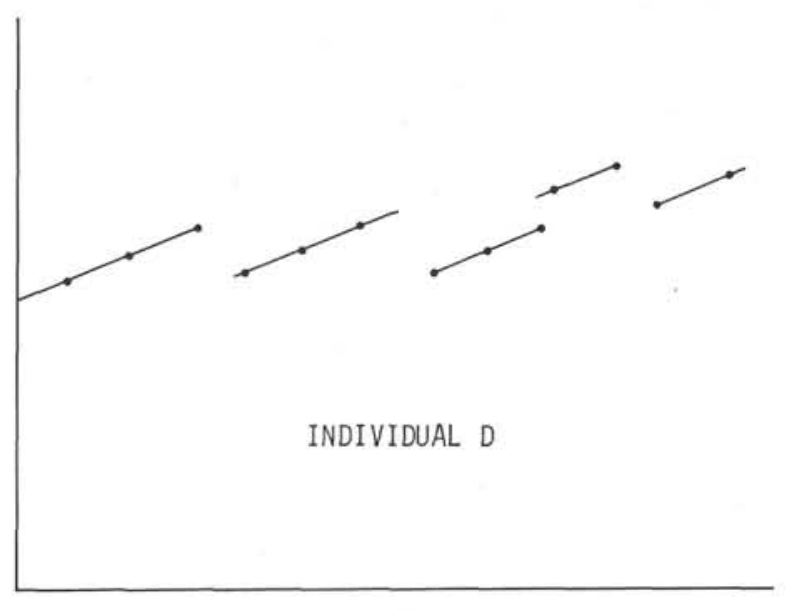

d

Figure 1. Growth patterns observed in planktonic foraminifera. Each point represents a chamber.

The growth pattern of $G$. pertenuis (Figure 3) does not appear to be as ordered as $G$. exilis and seems to follow a crude sine wave pattern of cycles of increases and decreases in chamber dimensions. Two waves, sometimes three, of growth are characteristic of an individual. Upon closer examination these growth waves can be observed to consist of a series of step-ups and step-downs in chamber growth involving one to three chambers. However, an allometric relationship of chamber growth dimensions remains, thus indicating that a consistent growth rate is controlling the growth of the chambers. The repeated step-ups and step-downs to different growth levels can be envisioned as necessary consequences of test construction of this taxon. In shells of relatively large size, high growth rates and the packing of chambers appear to lead to complex growth patterns. Size reduction of chamber dimensions is observed prior to termination of growth in $G$. pertenuis as well.

\section{STUDY IN VARIATION}

A glance at a number of specimens of Globorotalia exilis indicates a wide range of morphologic variability (Plate 2). The eye can perceive that differences exist between individuals, some great, some small; yet, it is difficult to explain exactly and to what degree one individual differs from another. A comparison of the growth ontogeny of individuals is one way in which one can gain a clearer understanding into the morphologic differences between individuals and the extent to which variation exists within the population. Table 1 gives measurement data on the last eight chambers of the eight specimens of $G$. exilis figured on Plate 2. Although the earlier formed chambers exhibit as much variation as do the later ones, it is the latter that are most visible to the observer. These are the ones used in identifying the individual of a species and where the 

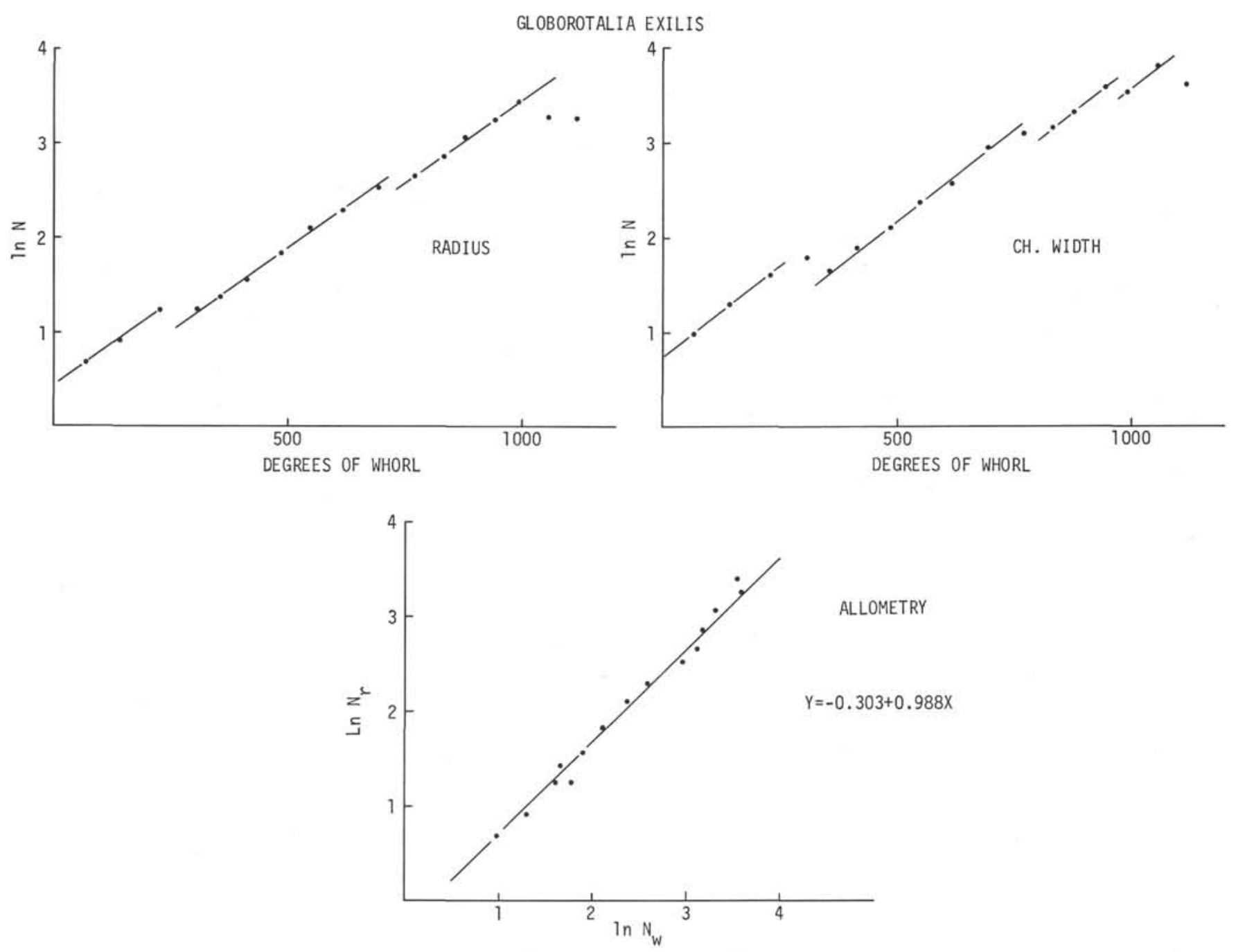

Figure 2. Growth pattern observed in Globorotalia exilis. Each point refers to a chamber. Growth curves and allometry curve are produced from measurements on specimen 645-10.

observer most often perceives the variation. Inspection of the table shows that the last 8 chambers do not represent the equivalent instar of growth in every specimen (i.e., the total number of chambers ranges from $14-22$ in this sample.) There are, however, greater similarities in the dimensions of chambers at the same position from termination of growth (ultimate chamber) than between equivalent instars (chambers) of growth. Contrast, for example, the dimensions of chamber No. 11 (Table 1) against all chambers in the same row as chamber 11 (specimen 645-9.) This suggests that test size is not correlated very strongly with number of chambers (compare specimen 645-9, Plate 2 , Figure 5 with $645-4$, Plate 2, Figure 3) but rather, that the expansion of chambers continues until the size limit of the species is reached. It is the total number of chambers and the growth sequence followed in an individual that leads to variation (the fewer the number of chambers the more quickly they expand in size, and vice versa) within the population. Inspection of the growth sequence of the final eight chambers of the eight specimens of Table 1 (see also Plate 2) illustrates the nature of morphologic variation. None of the growth sequences are identical. They differ because the angle of rotation (which is a reflection of size of adjacent chambers) at which chambers are secreted varies, because the sequence of angles of rotation is not the same in any two individuals, and because growth of chambers takes place at different size levels. Almost endless combinations of chamber arrangements consequently result, thus giving rise to a great variety of phenotypes. There is, nevertheless, an internal consistency in the growth of chambers of growth rates and of allometry. As can be observed in the allometric growth trend (Figure 4), the internal consistency is close, indeed.

\section{EVOLUTIONARY TRANSITION GLOBOROTALIA PERTENUIS-GLOBOROTALIA EXILIS}

Perhaps the most interesting evolutionary change that occurred during the transition of Globorotalia pertenuis 

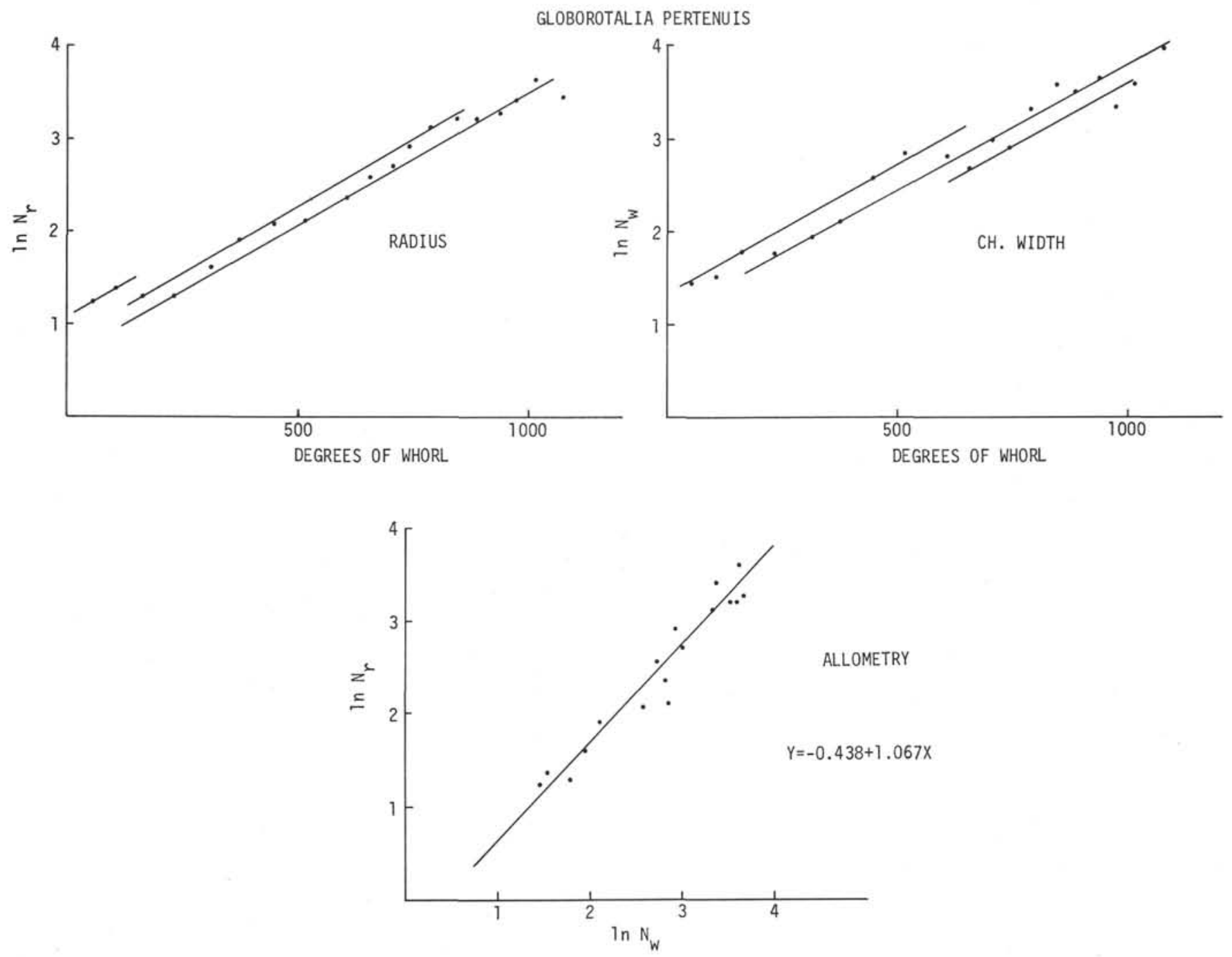

Figure 3. Growth pattern observed in Globorotalia pertenuis. Each point refers to a chamber. Growth curves and allometry curve are produced from measurements on specimen 647-3.

into Globorotalia exilis was the modification of the growth pattern from a simulated wave pattern in $G$. pertenuis to a series of step-downs to lower levels in $G$. exilis. The modification of the ancestral G. pertenuis growth pattern apparently came about by a stronger ordering of growth to a smaller number of growth levels. Thus step-ups in growth levels were reduced and chamber growth confined to intervals along certain growth levels. Actually, the growth pattern of $G$. pertenuis consists of a less ordered series of step-downs interrupted by intervals of step-ups in growth level. This pattern of repeated step-downs to lower growth levels appears to be a necessary consequence of high growth rates of chamber dimensions and the construction of large test sizes. High growth rates of chamber dimensions cannot be maintained at a high growth level throughout the ontogeny of an individual because chambers in the final whorls would become so large as to upset the summetry of the test and to yield an unwieldy morphologic form. Thus the step-down would appear to be an adaptation to maintain the symmetry of the test during growth. There also appears to be a space requirement of chamber size during its secretion. A careful reconstruction of the growth of an individual very often illustrates the requirement for a certain size value of a chamber in order to maintain an interlocking arrangement of chambers. Some size changes appear to be random, however.

Table 2 gives the important measurement data for each taxon during ontogeny. The allometry of radius to chamber width in $G$. pertenuis is positive, indicating that the radius dimension increases at a faster growth rate than does the chamber width. In G. exilis, allometry is nearly isometric so that in the transition to this species the growth rates of radius and chamber width became almost equal. Accompanying these changes in growth rates of chamber dimensions were others that effected the number of chambers and the angle of rotation. The average number of chambers in G. pertenuis is 19.1 and the average angle of rotation is 58 . In $G$. exilis it is 17.8 and 64 . The difference occurs largely in the third whorl of chambers as can be observed in Table 2. Here it can be seen that G. exilis has one less chamber and a larger angle of rotation. The chambers are not as tightly overlapped as in $G$. pertenuis. Figure 4 shows the allometric growth trend along which these growth changes took place. The two taxa are very close but definitely 
TABLE 1

Measurement Data on Last Eight Chambers of Eight Specimens of Globorotalia exilis

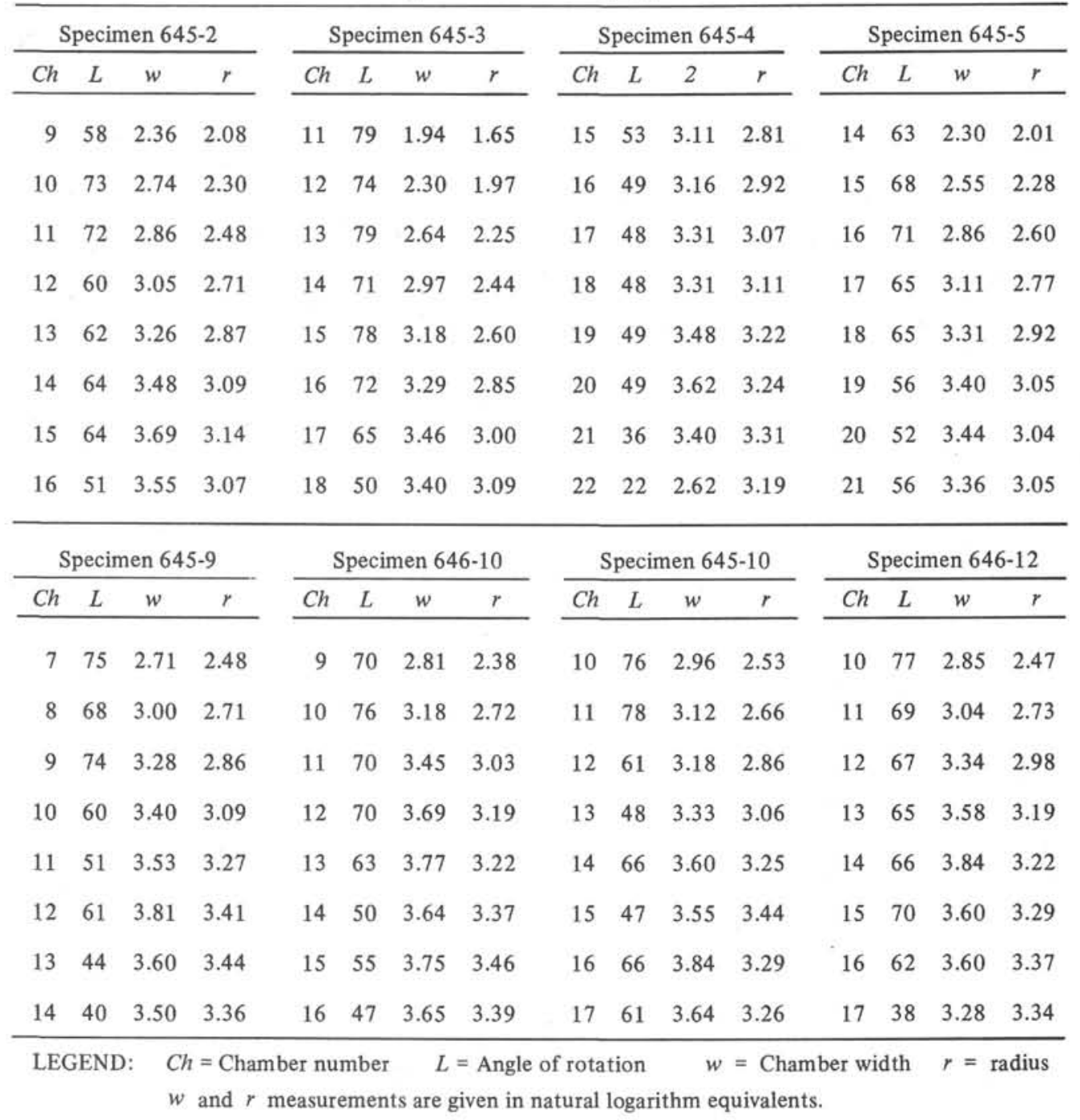

occupy two different positions on the allometric growth trend. Thus the morphologic changes of the transition can be considered minor but important with two recognizable end members. Possibly these changes were towards better adaption to the environmental niche of $G$. pertenuis or perhaps adaption was towards a slightly different niche position in $G$. exilis than in $G$. pertenuis.

\section{EXTINCTION OF GLOBOROTALIA EXILIS}

In a previous study (Olsson 1972) on the growth characteristics of the Miocene Globorotalia fohsi series, the step-down growth pattern was seen to appear in the last subspecies of the lineage prior to extinction of the lineage. One of the purposes of this study was to determine by study at different stratigraphic levels whether some recognizable change in the step-down pattern might have occurred just before the extinction of the species. The step-down pattern has been observed in cursory examination in other species of planktonic foraminifera with abrupt extinction levels. Although this growth pattern is as yet not clearly correlated with extinction, the association is common enough to warrant a closer study.

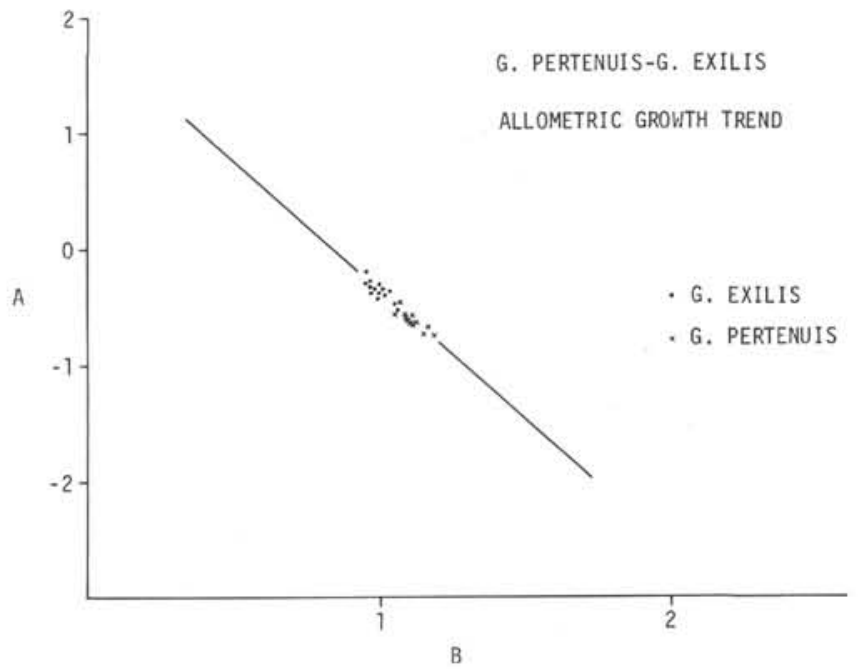

Figure 4. Plot of the allometric functions of 14 specimens of Globorotalia exilis and 9 specimens of Globorotalia pertenuis. 
TABLE 2

Summary of Ontogenetic Measurement Data of Globorotalia exilis and Globorotalia pertenuis

\begin{tabular}{l|cc}
\hline & G. pertenuis & G. exilis $^{\mathrm{a}}$ \\
\hline Radius 1n N. maximum & 3.44 & 3.31 \\
Chamber width In N maximum & 3.62 & 3.70 \\
Total degrees of whorl, ave. & 1089 & 1133 \\
Number of whorls, ave. & 3.02 & 3.15 \\
Angle of rotation, ave. & 58 & 64 \\
Total number chambers, ave. & 19.1 & 17.8 \\
Angle rotation 1st whorl, ave. & 68 & 68 \\
Number chambers 1st whorl, ave. & 5 & 5.14 \\
Angle rotation 2nd whorl, ave. & 64 & 67 \\
Number chambers 2nd whorl, ave. & 5.78 & 5.35 \\
Angle rotation 3rd whorl, ave. & 50 & 61 \\
Number chambers 3rd whorl, ave. & 6.89 & 5.78 \\
Angle rotation 4th whorl, ave. & 41 & 59 \\
Number chambers 4th whorl, ave. & 1.22 & 1.57 \\
B average & 1.108 & 0.995 \\
Allometry & + & \pm \\
Number of specimens & 9 & 14 \\
\hline
\end{tabular}

${ }^{\mathrm{a}}$ See Plate 2 for figures of these specimens.

The results of this study show that the step-down growth pattern of $G$. exilis developed from the less ordered step-down pattern of $G$. pertenuis. No apparent change is evident in the growth patterns of the phenotypes of $G$. exilis or $G$. pertenuis. The only change is from the one growth pattern into the other which has evolutionary if not paleoecologic significance. Since no change in growth pattern of $G$. exilis occurred that might indicate some type of growth response in the final parts of its range, it would seem that the step-down pattern itself is susceptible to extinction. Why this is so is uncertain, but possibly the attainment of this growth pattern may not allow sufficient adaptive genetic response to rapid environmental changes such as those that were occurring in late Pliocene time. The transition from the $G$. pertenuis pattern to the $G$. exilis pattern might be significant since it demonstrates that only minor growth changes are possible within this pattern. If this is so, then the development of a large overai test size, which seems to be positively correlated with this growth, has an immediate adaptive advantage. However, it is disadvantageous in time of environmental stress because limits have been preset in the genetic flexibility of this type of growth.

\section{ACKNOWLEDGMENTS}

The writer began his studies on growth on planktonic foraminifera while on academic leave at the Swiss Federal Institute of Technology. The study of the growth of the Globorotalia exilis group was suggested by Dr. H.M. Bolli who developed the Pliocene biostratigraphy in Hole 154A. Scanning electron micrographs were taken by Mr. H.E. Franz of the Geology Department of the Swiss Federal Institute of Technology. This work is partially supported by the Research Council of Rutgers University, New Brunswick, New Jersey.

\section{REFERENCES}

Bolli, H.M. 1970. The foraminifera of Sites 23-31, Leg 4. In Bader, R.G., Gerard, R.D. et al., 1960. Initial Reports of the Deep Sea Drilling Project, Volume IV. Washington (U.S. Printing Office). 577.

Olsson, R.K., 1971. The logarithmic spire in planktonic foraminifera: its use in taxonomy, evolution, and paleoecology. Trans. Gulf Coast Assoc. Geol. Soc. 21, 419. 1972. Growth changes in the Globorotalia fohsi lineage. Eclogae Geol. Helv. 65(1), 165. 


\section{PLATE 1}
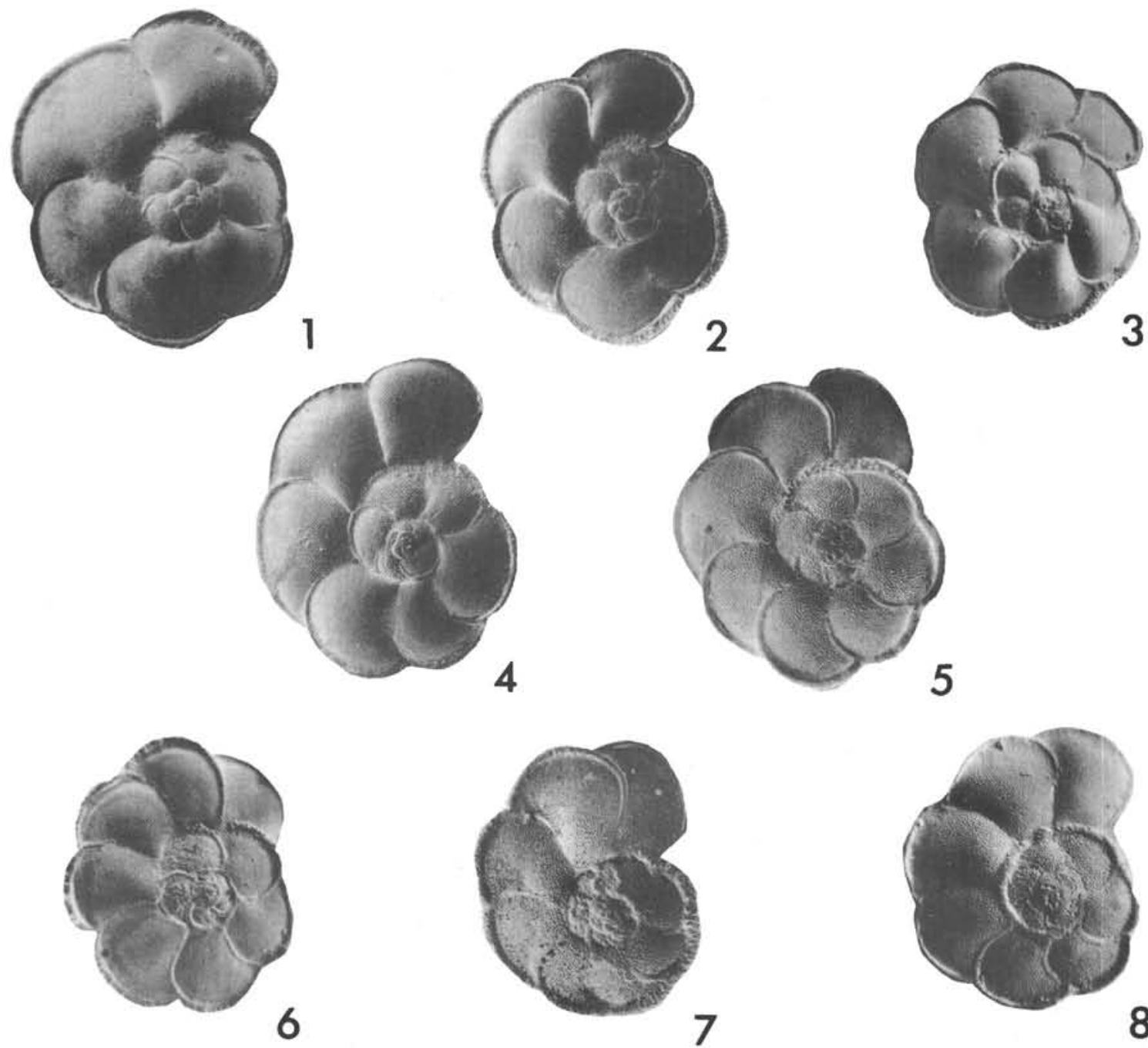

Scanning electron micrographs from which growth measurements are taken.

Figures 1-4 Globorotalia exilis Blow from Hole 154A: Figure 1 from Core 9 Section $222-24 \mathrm{~cm}$ ); Figures 2 and 3 from Core 10, Section 6, (100-101 cm); Figure 4 from Core 11, Section $3(40-42 \mathrm{~cm})$. Figure 3-X25; Figures 1, 2, 4-X40.

Figures 5-8 Globorotalia pertenuis Beard from Hole 154A; Figure 5 from Core 12, Section 1 (10-12 $\mathrm{cm})$; Figure 6 from Core 12, Section $3(17-19 \mathrm{~cm})$; Figure 7 from Core 12, Section 5 $(18-20 \mathrm{~cm})$; Figure 8 from Core 13, Section $5(18-20 \mathrm{~cm})$. Figures 6 and $7-\times 30$ : Figures 5 and $8-\times 40$. 


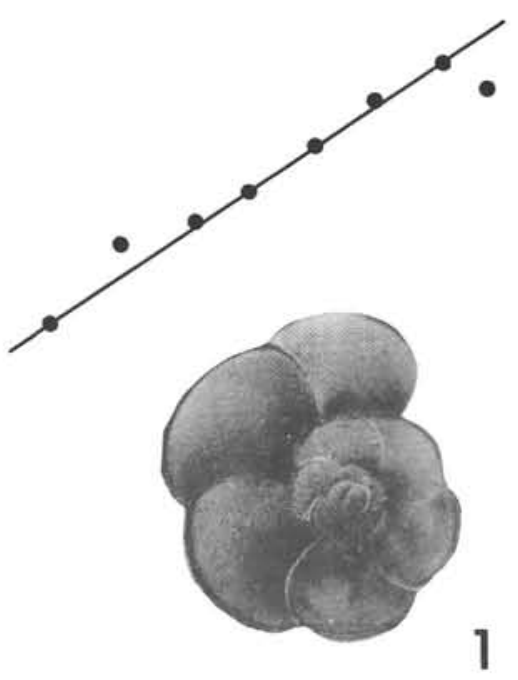

1

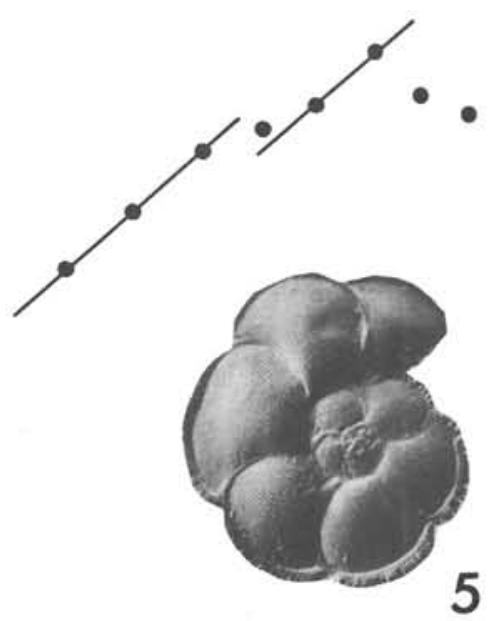

5

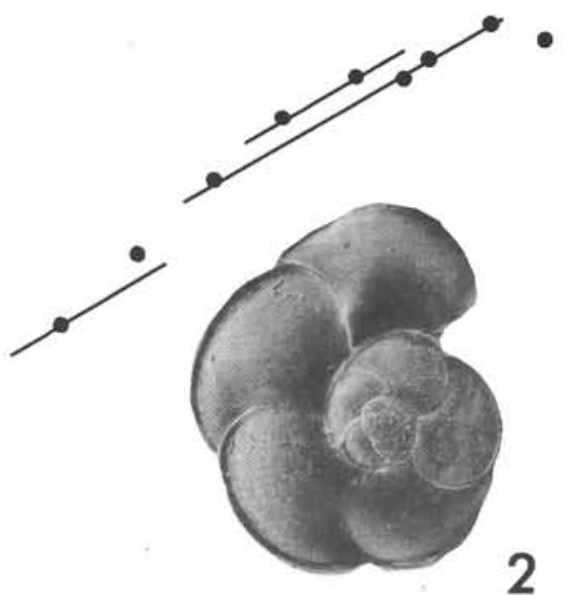

2

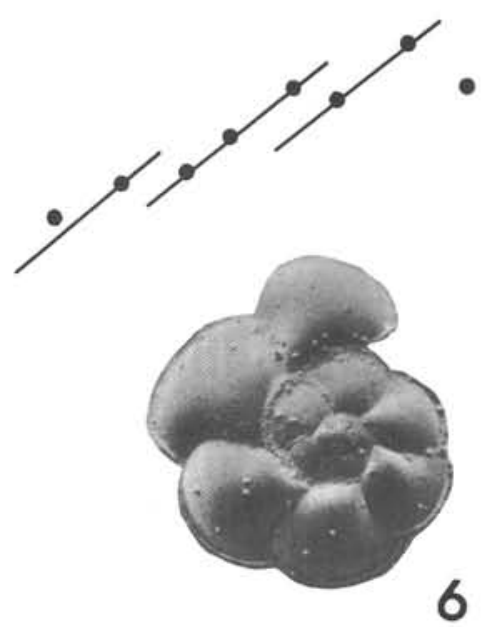

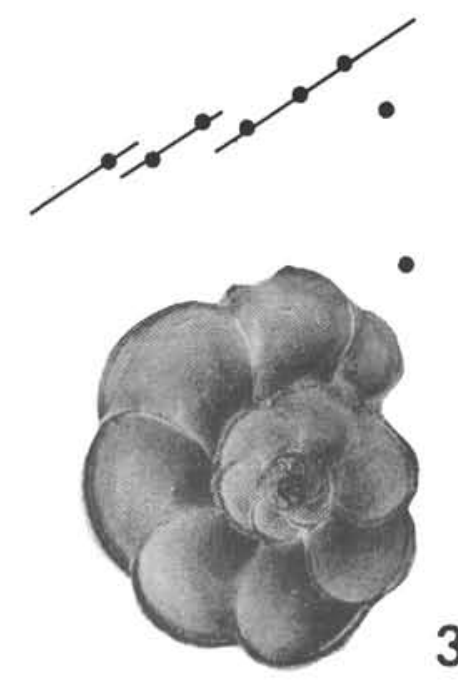
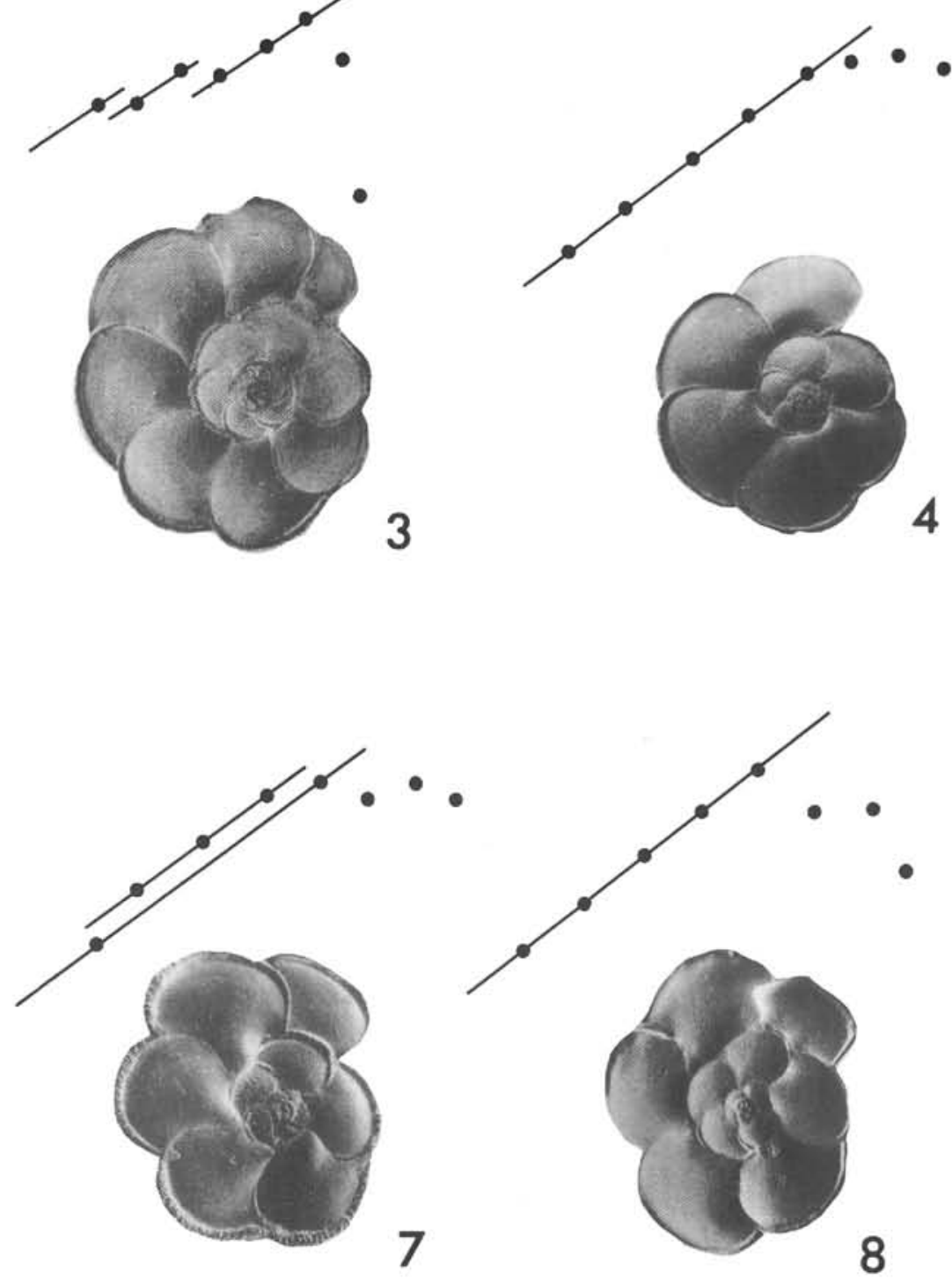

Scanning electron micrographs and growth data on chamber width of final eight chambers illustrating variation in Globorotalia exilis Blow from Hole 154A. (See Table 1 for statistics on these specimens) Figures 1 (sp. 645-2) and 2 (sp. 645-3) from Core 9, Section 2 (22-24 cm); Figures 3 (sp. 645-4) and 4 (sp. 645-5) from Core 9, Section 2 (102-104 cm); Figures 5 (sp. 645-9) and 6 (sp. 645-10) from Core 10, Section 2 (105-107 cm); Figures 7 (sp. 646-10) and 8 (sp. 646-12) from Core 11, Section $6(103-105 \mathrm{~cm})$. Figures 4 through $8-\times 30$; Figures 1 and $3-\times 40$; Figure $2-\times 50$. 